\title{
Algumas interferências numa conversa com Blanchot
}

Cid Ottoni Bylaardt

PPGLetras-UFC

Saulo de Araújo Lemos

FECLI-UECE

\begin{abstract}
Resumo
A obra do autor francês Maurice Blanchot (1907-2003) é, como se sabe, vasta e oscila entre classificaçóes diversas: crítica, prosa literária, filosofia. A partir da extensa coletânea ensaística L'entretien infini ("A entrevista infinita" ou "A conversa infinita"), será discutido o conceito de interferência na obra blanchotiana como o modo de conexão entre os gêneros discursivos mencionados acima e como modo de relação da literatura consigo mesma a partir da distância de si que a constitui. Esse propósito será efetivado pela leitura e discussão de passagens da longa seção de L'entretien infini intitulada "La parole plurielle" ("a fala plural”), composta de vários capítulos que associam o ensaio expositivo ao diálogo filosófico e em que conceitos diversos, mas próximos, interferem-se mutuamente ("fora", "neutro", desconhecido", "o impossível" "interrupção" etc.). Tal investigação oferece uma leitura possível a respeito da obra de Blanchot, obra que, em lugar de ser vitimada pelo impasse hermenêutico que acomete grande parte da crítica literária ocidental frente à obra literária, dirige-se resolutamente a esse impasse como acionamento de sua abertura crítica ao possível e ao impossível que a linguagem produz e abriga.

Palavras-chave: Maurice Blanchot; crítica literária; filosofia; interferência.
\end{abstract}

\section{Résumé}

L'œuvre de l'auteur français Maurice Blanchot (1907-2003), on le sait, est vaste et oscille entre des classifications diverses : critique, prose littéraire, philosophie. En partant du large recueil d'essais L'entretien infini, on discutera le concept d'interférence dans l'œuvre blanchotienne comme mode de connexion entre les genres discoursifs mentionnés ci-dessus et aussi comme rapport entre la littérature et elle-même en considérant l'écart de soi qui la caractérise. Ce propos sera effectué par la lecture et la discussion des passages extraites de la longue partie de L'entretien infini appelée "La parole plurielle ", composée par plusieurs chapitres qui mêlent l'exposé au dialogue philosophique, dans lesquels des concepts divers, mais proches, interferent mutuellement (" dehors ", " neutre ", " inconnu ", « l'impossible ", interruption »). Cette investigation offre une lecture possible sur l'œuvre de Blanchot, œuvre qui, loin d'être attrapée par l'impasse herméneutique dont une grande partie de la critique littéraire occidentale est prise devant l'oeuvre littéraire, se dirige de manière résolue vers cette impasse comme déclenchement de son ouverture critique au possible et à l'impossible que le langage produit et abrite.

Mots-clés: Maurice Blanchot; critique littéraire; philosophie; interférence. 
1. PROUST, Marcel. "Le temps retrouvé”, 1999, p. 2262-2263.

2. Blanchot, mesmo alimentado inicialmente pela fenomenologia, acaba se distanciado da associação um tanto automática que esta faz entre o sentido da visão e o dar-se atribuído ao fenômeno. O livro focado aqui, L'entretien infini, é um dos marcos desse movimento na obra blanchotiana.
Outro dia, eu estava conversando com um amigo sobre modos de percepção que vigoram atualmente no campo geral de nossa sociedade. Concordamos que hoje é raro o costume de assistir, por exemplo, a uma apresentação musical erudita por horas seguidas; parece até que nas últimas décadas, mais e mais, a descontinuidade tem sido imposta à percepção, ou por ela incorporada; por hábito, um observador alterna sua atenção entre estímulos dispersos; indício dessa situação é a maneira pouco atenta como muitas pessoas se comportam diante da televisão. Quanto ao uso da internet, então, nem se fala. O sujeito contemporâneo se faz e se projeta como um conjunto não-orgânico de seres ou fragmentos (ser é ser fragmento, hoje) para se observar. Vale notar, ainda, que muitas obras artísticas se aproveitam, faz muito tempo, do fenômeno da atenção dispersa. Isso é tanto um gesto de deboche à desatenção do público no mundo pós-industrial como um jeito de avessar os sentidos e expectativas habituais a respeito da falta de atenção, tornando-a uma significação deslocada. Isso tem ocorrido de maneiras muito distintas, e o que aqui é identificado não passa, obviamente, de uma ocorrência a mais. Trata-se de uma espécie de regra da desatenção. Um exemplo isolado: o narrador proustiano, em Le temps retrouvé [O tempo reencontrado, último volume de Em busca do tempo perdido], ao chegar à mansão do príncipe de Guermantes, tropeça num paralelepípedo desnivelado e, por um momento, seu corpo e seu olhar ficam em posição oblíqua enquanto os pés se apoiam em paralelepípedos de alturas diferentes; isso lhe causa a mesma sensação de quando caminhou sobre um trecho irregular do batistério de São Marcos, em Veneza; então ele percebe inesperadamente que a arte talvez lhe fosse acessível e que ele poderia ser escritor ${ }^{1}$. A atenção do personagem, naquele momento, perde o fio da situaçáo presente e ele, num breve instante, não está na mansão Guermantes, nem em Veneza; o signo suspeito dessa experiência é seu relato, que, assim, é tão intenso quanto banal. Intensidade e banalidade, aqui, se interferem mutuamente. Algo interfere em sua atençấo, algo a captura, e o sujeito é levado a um lugar construído inadvertidamente por ele mesmo no plano de seu devaneio.

$\mathrm{O}$ texto como fragmento tem sido muito sinalizado e comentado desde o romantismo, no século XIX. Os irmáos Schlegel e Walter Benjamin são algumas referências destacadas a respeito. Essas duas mençôes já sugerem um trajeto no qual o fragmento parte de um papel subsidiário para se tornar, via materialismo dialético, o todo possível, a própria realidade, a formulação mais plausível do que seria a coisa em si. Para a fenomenologia, em seus desdobramentos pré, durante e pós-Heidegger, se o fragmento náo é a revelaçáo plena do ser, ele não deixa de atuar como sua potência, promessa mantida na própria suspensão. Assim, vários passos da obra do francês Maurice Blanchot ${ }^{2}$ 
são oportunos ao exercício de um pensamento sobre a prática da desatençâo e do contínuo reatentar para alguma coisa com a qual os jogos de cultura, especialmente os artísticos, têm se armado desde a grade crise da mentalidade clássica-universalista-metafísica ocorrida no século XIX. Um tema que percorre grande parte da obra de Blanchot é o de que a linguagem, e seu correspondente assimétrico, o humano, são construções móveis, cujas peças mudam de posição e de valor e se relacionam de maneiras que tendem a escapar de determinaçóes a priori; isso, já que o humano e a linguagem teria como essência não a sua matéria orgânica-significante, mas o vazio de assignificação que linda permanentemente com essa matéria e a dirige ao devir de si própria, contínua expectativa de auto-extrapolação. Os sistemas de cultura, assim, podem esvair-se dentro de si mesmos; o trio autor-obra-leitor, por exemplo, não seria garantidamente um circuito de autoalimentação dialética ${ }^{3}$, mas principalmente a iminência de crises constantes e relativamente insolúveis; muitas vezes, a atitude do autor é de tentar dominar os sentidos da obra que produziu; já o leitor tende a procurar se impor à obra, fazer dela sua imagem e semelhança; enquanto isso, a obra, arredia, apenas temporariamente se deixa aprisionar pelas investidas de autores e leitores, porque se afirma e se reafirma mediante seu potencial de emancipação dos contextos que eventualmente a abrigam; isso porque ela, a obra, torna a insuficiência um modo de presença e se faz com lacunas que outras manifestaçôes de linguagem náo aceitam do jeito que ela aceita ${ }^{4}$. Assim, os sistemas literários entram em curto-circuito com frequência por conta de sua própria constituição. Os fluxos de cultura são cheios de desvios, interrupçōes, interferências.

Nos termos apresentados, a apreciação de Blanchot para a relaçáo entre obra, autor e leitor sugere que eles convivem de forma potencialmente agressiva, já que a paz ente os três, comumente, é armada, é um tipo de hostilidade virtual. $\mathrm{O}$ trio pode até cooperar consigo mesmo, pode haver mútua alimentação, mas também disputa por hegemonia, tentativa de se sobressair, afirmar-se a partir do que confunde e atrapalha o vizinho. É óbvio que a literatura não é uma entidade atuante como um indivíduo leitor ou um autor, mas pensá-la como tal pode fazer lembrar que ela não está à completa e permanente mercê dos sujeitos empíricos, individuais ou coletivos, que a produzem ou usufruem dela. O percurso social da obra literária pode ser de transparência e complementaridade, mas também de desvio e acidente. A hierarquização entre obras ou entre obra, autor e leitores pode até existir, mas segue a tendência de se refazer e se desfazer sem um direcionamento preciso. Essas sinalizaçóes apontam, como estímulo de inquietação, à hipótese de que uma entidade cultural qualquer interage com outra, encadeada a ela, a partir do que se pode chamar de interferência, que é a pressão
3. Proposição fundamental ao popular conceito de "sistema literário", apresentado em: CANDIDO, Antonio. Formação da literatura brasileira: momentos decisivos, 2000.

4. Cf. BLANCHOT, Maurice. L'espace littéraire, 2012. 
5. WITTGENSTEIN, Ludwig. Investigações filosóficas, 2005, p. 70.

6. LOPES, Silvina Rodrigues.

Literatura, defesa do atrito, 2012, p. 137-139.

7. Cf., e.g., nota de rodapé em BLANCHOT, Maurice. L'espace littéraire, 2012, p. 294.

8. Isso, após um brevíssimo prefácio em que o autor considera a escritura-literatura como permanente promessa de ultrapassagem dos limites do que se chama Livro, Eu, Sujeito ou Deus, conceitos que carregam uma espécie de ânsia pelo absoluto, pela simbolização plena de si, pela ideia de "un ordre soumis à l'unite" ["uma ordem submetida à unidade”]. BLANCHOT, Maurice. "La parole plurielle”, 1969, p. VII. exercida de cada lado e é também, como resultado dessa pressão, o que Ludwig Wittgenstein ${ }^{5}$ aponta como a tendência ao atrito na linguagem em geral, atrito esse que Silvina Rodrigues Lopes ${ }^{6}$ observa naquilo que por uso se nomeia literatura; em geral, um leitor se encontra com uma obra quando ocorre a interferência chamada leitura, interferência de mão dupla (ou mão múltipla) que, percebe-se, não marca nem privilegia, necessária ou permanentemente, nenhum dos elos encadeados.

A interferência como deslocamento de foco, automovimento do texto, é peculiar a muitas abordagens críticas que Blanchot faz de diversos autores; mais que isso, é também uma estratégia metodológica que alimenta muitos dos seus textos e que passeia pelo conjunto de sua obra. $\mathrm{O}$ autor francês, como Borges, não se limitou a explorar gêneros diversos, mas defendeu e praticou uma mais ou menos aguda implosão das fronteiras habituais entre eles ${ }^{7}$; a poesia e a proposição filosófica interferem-se de modos variados e inesperados em sua produção. Em certas obras, fica difícil dizer onde uma começa e a outra acaba; aliás, na medida em que se conhece a obra de Blanchot, essa distinção é cada vez menos relevante (na contramão dos rituais e da praticidade cotidianos, que costumeiramente criam uma necessidade pelos gêneros). Um caso especial de deslocamento e interferência como realização de texto, na escrita blanchotiana, é o de L'entretien infini ["A conversa infinita" ou "A entrevista infinita"], longo texto feito de textos díspares. Nele, o foco se move da literatura à filosofia, da política à estética, e sugere que o saber pode ser um despojamento do saber e um gesto, possivelmente resoluto, de desatençáo - seja esta uma recusa deliberada, seja ela uma rendição ao que na obra seduz e traz o imprevisto. Mais de dez anos após a morte de Blanchot, propóe-se aqui compartilhar anotaçôes a partir da primeira parte de L'entretien infini, chamada "La parole plurielle" ["A fala plural"], plano-conjunto de vários capítulos curtos. A fala é plural? Qual fala é plural? $\mathrm{O}$ que ela e isso dizem?

L'entretien infini começa ${ }^{8}$ por um texto em prosa em que dois personagens conversam desde um tempo remoto, ignorado, mas que talvez esteja perto de terminar. Um dos dois já tem a idade bastante avançada, a fadiga de ambos é evidente. Estáo lado a lado em uma mesa circular. Ambos, num instante tal, percebem que a fadiga é experiência aguda, mudando a autopercepção do corpo, a percepção de suas fronteiras habituais por ele mesmo; percebem que a fadiga é o que motiva sua entrevista. Em alguns momentos da conversa, narrada em terceira pessoa com enxertos em primeira, não se sabe quem fala e quem escuta, se as palavras estão sendo pronunciadas ou pensadas, se há um sentido ou sentidos para o que se está dizendo; não se sabe, dos interlocutores, quem é quem, ou o que os distingue; sabe-se que eles são distintos, que, juntos, é como se algo faltasse ou sobras- 
se, não havia certeza quanto a isso. Em respeito a isso, a conversa se costura com o que transita da conveniência à impertinência, do lugar-comum à indefinição de lugar que é o diálogo entre esses personagens. Movimentos, ritmos misturados, passeiam por essa prosa: riscam um círculo ${ }^{9}$ nessa escrita, mas permitem que ele se quebre, que se interrompa. $\mathrm{O}$ trecho a seguir tem a ver com isso:

Ele se lembra em que circunstâncias o círculo foi traçado como que em volta dele - um círculo: antes uma ausência de círculo, a ruptura dessa vasta circunferência de onde vêm os dias e as noites. Deste outro círculo, ele sabe somente que não está preso nele e, em todo caso, que ele não está preso nele consigo mesmo. Ao contrário, o círculo que se traça - ele se esquece de dizê-lo; o traço começa somente não lhe permite se incluir nele. É uma linha ininterrupta $\mathrm{e}$ que se inscreve ao se interromper. ${ }^{10}$

A interrupção traz o risco e a crise à entrevista, mas também permite a ânsia de fuga da prisão de insegurança máxima que é a linguagem pós-romântica, ou moderna, ou pós-moderna. Por acidente, na necessidade súbita do acidente, o diálogo se interrompe, suspende-se, indefinidamente, e eles mudam de assunto e sentem o cansaço da experiência própria. No entanto, é esse cansaço que alimenta a conversa. As interferências da fadiga e do interlocutor ameaçam e estimulam a fala; de todo modo, náo há garantia de que a interferência seja uma lei de sobrevivência do discurso, e a expectativa é que em algum momento haja algo como um fim, "le coeur cessant de battre, l'éternelle pulsion parlante s'arretant" ["o coração parando de bater, a eterna pulsão falante parando $]^{11}$, interferência fatal, fim plausível da própria interferência. A interferência do outro se mistura à indefinição do eu (interferência suplementar), o qual não sabe bem o que responder ao interlocutor; ambos precisam daquela conversa para existirem, portanto. O diálogo entre os personagens é uma pequena ficçáo que age no livro como um prefácio postiço; em seguida, começa a primeira das três grandes partes do livro, aquela que se chama "La parole plurielle". A seção se divide em capítulos que abordam questóes próximas, ligadas à fundação do pensamento no Ocidente: a gradual assunção do fragmento, num percurso que passa por Kierkegaard e Nietzsche, como acesso privilegiado ao real; a postulação da escritura como contínua pergunta, mesmo quando resposta; o diálogo entre pensamento e escritura, no Ocidente, como propulsionado pelo desajuste entre ambos; a sacudidela que a escritura provoca no sensóreo da experiência, inclusive no olhar como revelação sustentado pela fenomenologia; etc. $\mathrm{O}$ correr das páginas não aponta uma progressão dialética, masuma justaposição de abordagens um tanto desencontradas, mais perto do parágrafo-labirinto de Nieztzsche
9. Perguntar, esperar resposta, isso é o que traça o círculo no diálogo, o que faz um diálogo um círculo.

10. "Il se rappelle dans quelles circonstances le cercle fut tracé comme autour de lui - un cercle : plutôt une absence de cercle, la rupture de cette vaste circonférence d'où viennent les jours et les nuits. De cet autre cercle, il sait seulement qu'il n'y est pas enfermé et, en tout cas, qu'il n'y est pas fermé avec lui même. Au contraire, le cercle qui se trace - il oublie de le dire; le trait commence seulement - ne lui permet pas de s'y comprendre. C'est une ligne ininterrompue et qui s'inscrit en s'interrompant". BLANCHOT, Maurice. "La parole plurielle", 1969 , p. XVI. Todas as traduções são de nossa autoria.

11. Ibidem, p. XXVI. 
12. La parole plurielle é uma longa seção, composta de capítulos com abordagens diversas para certas linhas de questionamento, talvez próxima da maneira como está resumida nesta fala. Discutir fragmentos soltos de texto, como que ao acaso, em lugar de um recorte mais habitual como um capítulo ou um conceito, seria um modo aceitável de exemplificação do texto blanchotiano como uma continuidade ativada pela interferência entre fragmentos, fio que vibra em ondas que sacodem sua plausível extensão de fio?

13. Somente com os sentidos físicos se pode dimensionar, com margem de erro, aquilo que na escritura desloca e atordoa os sentidos corpóreos e individuais, aquilo que nela ainda está por receber um sentido, aquilo que faz do humano algo que não se enquadra tranquilamente na palavra humano.

14. Ibidem, p. 5.

15. Ibidem, p. 21; 32; 67.

16. Ibidem, p. 61-64; 68-69.

17. Ibidem, p. 45; 64-68.

18. Ibidem, p. 70-83.

19. DERRIDA, Jacques.

"Restitutions de la vérité en pointure", 1978. que de uma pirâmide dialética hegeliana; sáo literalmente textos dispersos e postos em sequência, de modo a se perturbarem mutuamente pela leitura: ensaios, diálogos (os personagens parecem retomar a conversa já enunciada no prefácio, percorrendo os temas mencionados de modo não linear). A discussão de " $L a$ parole plurielle"12 é na verdade vasta e heterogênea; dela, alguns fragmentos vão ser colhidos e examinados ${ }^{13}$.

Observando alguns momentos da história da filosofia ocidental, Blanchot aborda em primeiro lugar a vertente do pensamento contínuo, progressivo, afiliado a uma necessidade didática convencionada, comungada por Platão e Sáo Tomás de Aquino, dentre outros. Sören Kierkegaard e Friedrich Nietzsche, por sua vez, encarnariam uma tendência que teria começado com Pascal: a do pensamento que, como condição de existência, é fragmentado. As obras com essa tendência firmariam, na opinião de Blanchot, a relação entre o mestre e o discípulo como uma desigualdade, não por uma pretensa superioridade do primeiro, mas por um desnível que há entre ambos na medida em que o conhecimento envolve um aparente procedimento de transferência, mas que na verdade é desencadeamento, detonação. "Le maître n’est donc pas destiné à aplanir le champ des relations, mais à les bouleverser; non pas à faciliter les chemins du savoir, mais d'abord à les rendre non seulement plus difficiles, mais proprement infrayables" ["o mestre não é portanto destinado a aplainar o campo das relaçôes, mas a bagunçá-las; não a facilitar os caminhos do saber, mais antes a torná-los não somente mais difíceis, mas propriamente intransponíveis"] ${ }^{14}$; o mestre filósofo acolhe e estimula a inquietação; ele provoca e perturba o aluno, torna sua existência de aluno uma impossibilidade, mas também uma necessidade de deslocamento ou busca por um lugar próprio, por um outro lugar, por pensar o lugar e o não ter lugar. $\mathrm{O}$ abismo entre professor e aluno pode levá-los a se mover tanto em ritmos semelhantes como díspares, produzindo e extrapolando o círculo. Daí pode aparecer a hipótese de o pensamento ser a forma da inconstância formal, do discurso como autodesrespeito (sendo crítica ou sendo censura, por exemplo), pensamento como forma fundamental da linguagem, mesmo que eventualmente misturada a tempos ou espaços quaisquer. Para Blanchot, certamente, a linguagem não é caracterizada por seus conteúdos, sempre cambiantes, mas pelo aspecto informe que é sua dimensão "neutra"15, marcada pelo elemento "impossível"16 da linguagem, que é seu "fora" 17 e é também o "desconhecido"18, aquilo que não tem lugar visível, ausência disseminada ao longo da linguagem, e que a mantém incompleta porque dispersa de si. O neutro (fora, impossível, desconhecido) é aquilo que pressiona a escritura contra os conteúdos, tempos, espaços e corpos que a compóem, pelo lado de fora, pelo não-lado, pelo que não parte da escritura, e que não é simplesmente o contexto, 
o momento histórico ou o leitor, mas o fator de risco embutido na própria iniciativa de delimitar uma escritura em obra. O neutro (fora, impossível, desconhecido) é o desfazer-se até-agora de toda obra, é a sobrevivência até-agora de toda escritura como não-escritura, como extravio. É a garantia de que toda escritura, se escritura artística, é extraviada de alguma forma, é pensamento do extravio de várias categorias-irmãs na história da cultura ocidental: sujeito, espírito, Deus, essência, universalidade.

O caráter imprevisivelmente neutro que o pensamento pode assumir náo é necessariamente imune ao que Jacques Derrida ${ }^{19}$, em La vérité en peinture (1978), identifica como impulso à "restitution" de um bem cultural a seu suposto dono. Esse modelo de restituição, mito de uma origem inexistente, é exemplo de uma pulsão subjetiva unificadora, que ao menos eventualmente consegue fechar, pela força ou pela sedução, círculos em que subjetividade $=$ unidade, gesto peculiar à tradição metafísica ocidental ${ }^{20}$ : o vetor subjetivo, seja ele um indivíduo ou um grupo qualquer, usualmente procura inscrever sua marca, sua rasura, como se produzisse um círculo fechado (uma cosmogonia), sobre dimensões de experiência ou de escrita que de algum modo lhe sejam alheias; essa força subjetiva, assim, tenta inscrever uma imagem de si mesma sobre a alteridade como se fizesse um transplante dela própria no outro; Cada indivíduo, com o que diz ou escreve, tenta e eventualmente consegue rasurar o texto de cultura meio geral, meio vago, que o envolve e que ele, por si, apesar dos esforços que faça, não consegue tiranizar. Ser ou estar sujeito é tentar deixar uma marca própria, como uma rasura, marca que pode ou não perdurar por algum tempo imprevisto; o círculo se faz esfera, bolha de sabão pronta ao estouro, ao transbordamento de si. A ação subjetiva, menos coesa e menos fictícia que a noção tradicional de sujeito, é um derramamento, é a descontinuidade pondo o círculo em risco apesar de toda a inércia contida nessa crença chamada subjetividade ${ }^{21}$. A rasura subjetiva pressiona a potência impessoal e desagregadora da linguagem; aquilo que não pode ser riscado realiza, entáo, uma contrarrasura, uma rasura inversa, uma rasura da rasura, um plano de rasuras. Ambas parecem precisar uma da outra para existirem, sua convivência cria uma espécie de plano de tensão, uma potência de tumulto. A arte é um dos palcos dessa performance subjetiva descentrada, aguçadora daquela potência de tumulto, duplo de si mesma, positividade em devir, negatividade como presente à materialidade trivial da estrutura, do objeto, do artefato ${ }^{22}$.

O círculo (a continuidade) e a sua quebra (a descontinuidade) são tensões vetoriais igualmente comuns no jogo da cultura, embora ainda se privilegie o primeiro como verdade estável; o contínuo, na perspectiva da totalidade, daquilo que ultrapassa o olhar humano, seria então supostamente a realidade efetiva
20. Sobre o conceito de metafísica ocidental como essencialismo associado à simbolização como presença automática/mágica do eu, ver DERRIDA, Jacques. De la grammatologie, 2011.

21. Paul de Man, em "Impersonality in the criticism of Maurice Blanchot", considera que a abordagem da tendência impessoal na obra do autor francês seria um "preparatory step in his hermeneutic of the self" ("passo preparatório em sua hermenêutica do eu”), já que o procedimento da leitura requer por princípio, um "return toward a subject that, in fact, never ceased to be present" ("retorno a um sujeito que, de fato, nunca cessou de ser presente"). MAN, Paul de. "Impersonality in the criticism of Maurice Blanchot", 1983, p. 78. A questão que parece mais relevante não é a da inexistência desse sujeito, mas, num sentido que Man não toca, a da sua não-unidade prévia, da sua possibilidade de cisão ou descontinuidade, sua possibilidade de interferir em si mesmo a partir daquilo que nele é externo, desconhecido, impossível: a partir, enfim, de sua instabilidade. A linguagem literária mais antiga talvez já aponte, para prejuízo de boa parte da produção mundial em ciências humanas nos últimos séculos, uma abordagem do sujeito nessa perspectiva: o personagem de aparência mais coerente nunca é rigorosamente fechado ou linearmente determinado, fixo; um personagem constituído por uma única característica é já um fragmento, uma sinalização em devir, um círculo pronto ao deterioramento.

22. Sobre a obra de arte como afirmação essencialmente negativa, ver BYLAARDT, Cid Ottoni. "Negatividade e morte no pensamento de Maurice Blanchot", 2013, p. 182-190. 
23. "[...] por que o homem, supondo que o descontínuo lhe seja próprio e seja sua obra, não revelaria que o fundo das coisas ao qual é bem necessário que ele de qualquer modo pertença, não tem menos a ver com a exigência da descontinuidade que com a da unidade? quando se fala do homem como de uma possibilidade não unitária, isso não quer dizer que permaneceria nele qualquer existência bruta, qualquer natureza obscura, irredutível à unidade e ao trabalho dialético: isso aqui está fora do problema. Isso quer dizer que, pelo homem, quer dizer, não por ele, mas pelo saber que ele porta e a princípio pela exigência da fala sempre já previamente escrita, seria possível que se anunciasse uma relação de todo outra que ponha em causa o ser como continuidade, unidade ou agrupamento do ser, ou seja, uma relação que se excetuaria da problemática do ser e proporia uma questão que não fosse questão de ser”. Ibidem, p. 11. contra a qual a percepção humana, descontínua, estaria em choque. Blanchot, por sua vez, considera que tanto a continuidade (ou unidade, ou totalidade) como a descontinuidade (ou fragmentariedade, ou parcialidade) seriam imagens criadas tanto pela percepção como pelas linguagens em obra que ela percebe, inclusive a artística. É assim que ele pergunta:

pourquoi l'homme, em supposant que le discontinu lui soit propre et soit son oeuvre, ne révélerait-il pas que le fond des choses auquel il faut bien qu'en quelque façon il appartienne, n'a pas moins affaire à l'exigence de la discontinuité qu'à celle de l'unité? Conclusion troublante, trouble aussi et que dès maintenant nous chercherons à preciser em ajoutant : quand on parle de l'homme comme d'une possibilité non unitaire, cela ne veut pas dire que demeurerait en lui quelque existence brute, quelque obscure nature, irreductible à l'unité et au travail dialectique : cela est ici hors problème. Cela veut dire que, par l'homme, c'est-à-dire non par lui, mais par le savoir qu'il porte et d'abord par l'exigence de la parole toujours déjà préalablement écrite, il se pourrait que s'annonce un rapport tou autre qui mette em cause l'être comme continuité, unité ou rassemblement de l'être, soit un rapport qui s'excepterait de la problematique de l'être et poserait une question qui ne soit pas question de l'être. ${ }^{23}$

Nem continuidade, nem tampouco a descontinuidade, entendidas/afirmadas como dimensôes originárias, dão conta do humano e sua dimensão humana/inumana de linguagem. Nenhuma é necessariamente a essência do humano ou da linguagem. A experiência como significaçăo só será possível a partir dessa constataçáo, que pode ser acionada pelo exercício de enunciar questóes. $\mathrm{O}$ corriqueiro ato de questionar, segundo Blanchot, associa-se com frequência à tentativa de sintetizar um questionamento sobre o todo do real ("la question d'ensemble" - "a questão de conjunto"); entretanto, a pergunta unificada sobre o ser, em suas tantas modalizaçóes, costuma deixar escapar uma questáo suplementar sobre por que todas as perguntas juntas não respondem tudo - essa seria o que Blanchot nomeia "la question la plus profonde", a questão mais profunda, que não se tem coragem de perguntar ou sequer chega a ser pensada. A questão mais profunda é o próprio horizonte da linguagem, é a persistência da escritura quando não há mais escritura, quando não há sentidos. A resposta, seja qual for o programa a que ela se adéque ou faça apelo, é sempre incompleta, e a incompletude estimulada pela pergunta assumiria o papel daquilo que existe como o porvir sem forma alguma, o poder neutro, acima de qualquer forma, mas nela disfarçado. $\mathrm{O}$ neutro, que pode ser também a pergunta irrespondida e informulada, parte da experiência sensorial mais tensa, da crise, do horror, da arte. 
Michel Foucault diz, em "La pensée du dehors" ["O pensamento do fora"], ensaio dedicado à obra de Blanchot ${ }^{24}$, que a literatura seria uma prática de linguagem como "passage au 'dehors"'25. Ao longo da obra de Blanchot, a imagem, mecanismo fundamental da obra de arte (e que termina por se confundir com esta), é apresentada como simulacro explícito da realidade, da experiência dita real, por produzir sensaçôes e emoçôes associados àquela, embora distintos, irreais; a própria ideia de uma totalidade que nos ultrapassa seria um tipo de imagem na concepçáo blanchotiana. Foucault, entretanto, considera que "les fictions chez Blanchot seront, plutôt que des images, la transformation, le déplacement, l'intérmediaire neutre, l'interstice des images" ("as ficçôes, em Blanchot, serão, mais que imagens, a transformação, o deslocamento, o intermediário neutro, o interstício das imagens" $\left.{ }^{\prime 26}\right)$. Para a imagem, a experiências sensorial/emocional é um gatilho, mas também uma impossibilidade; a coincidência entre ambas, imagem e experiência, é um lance incerto, um jogo de dados; a linguagem é que risca um limiar entre ambas; nisso se produz um jogo de interferências recíprocas. A linguagem, sem ser efetivamente experiência, interfere nesta, e vice-versa. Tal fato faz do filósofo, como diz Blanchot, "quelqu'un qui a peur" ["alguém que tem medo"] ${ }^{27}$. O medo, se não é a intensificação do humano, é talvez a intensificação de seus rastros:

la peur, qu'elle soi lâche ou courageuse, fraye - si vous permette ce jeu de mots - avec l'effrayant, et l'effrayant, c'est ce qui nous fait sortir à la fois de la paix, de la liberté et de l'amitié. Par l'effroi, nous sortons donc de nous-mêmes et, jetés au dehors, nous faisons l'expérience, sous l'espèce de l'effrayant, de ce qui est tout à fait en dehors de nous et autre que nous : le dehors même. ${ }^{28}$

O filósofo, o crítico, é, antes de ser o produtor de um pensamento ou de uma obra, aquele que experimentou a inquietaçáo com alta intensidade. Alguém a quem a linguagem acaba por escapar, ou que a deixa escapar, ficando a experiência crítica da hipersensibilidade como rastro e resultado disso. O que assusta o filósofo? Em outras palavras, o que assusta o crítico literário? A resposta indefinitiva a essa questão parece ser: o outro, a diferença, aquilo que se furta a qualquer determinação, mas pode vir inesperadamente a qualquer momento, aquilo que tanto é a grande redenção como o colapso definitivo ou não é nada disso. Assim, a arte é talvez menos determinável que outras linguagens, e por isso, em todo seu poder, talvez a mais impotente; é a que se exime de toda responsabilidade e transfere, em sua mudez relativa, a máxima responsabilidade ao humano, responsabilidade que ele ainda não sabe se pode assumir, responsabilidade sobre si mesmo. Assim, o poema é a pergunta mais forte, assim como
25. FOUCAULT, Michel. "La pensée du dehors”, 2001, p. 548.

24. Escrito em 1966, portanto quatro anos antes da publicação de L'entretien infini, o ensaio de Foucault é no entanto, de acordo com informações de Bident (1998), contemporâneo das discussões blanchotianas dos anos 1960, que afinal compuseram o livro tomado como objeto deste artigo. Isso, claro, sem contar a recorrência de conceitos como o de "fora" em obras anteriores de Blanchot.

26. Afirmação ambígua que, sem precisar uma menção à crítica ou à criação literária de Blanchot, marca uma linha de interferência mútua entre ambas, como o interstício em que uma pode atuar como imagem da outra, assim como a crítica literária, mesmo a mais tradicionalmente hermenêutica e explicativa, não é outra coisa além de imagem da obra que toma por foco. Ibidem, p. 552.

27. BLANCHOT, Maurice. L'entretien infini, 1969, p. 70.

28. Ibidem, p. 70. 
a linguagem de muitos jogos infantis. Pergunta suspensa, a arte prejudica a alternância cíclica entre o visível e o invisível, a luz e a sombra, como fronteiras do sensorial e da experiência; o que se vê e o que se esconde não são garantia de resposta à arte e ao próprio humano. A fala da literatura é o poder inverossível, mas real, de atuar como interferência a si mesma: ela é tal como Admeto, o mortal que, sob a maldição de Apolo, deve, ao pensar algo, pensar também simultaneamente seu oposto, e assim "parler doublement dans un même acte de language" [falar duplamente em um mesmo ato de linguagem $]^{29}$, conversando consigo mesmo eternamente sem nunca chegar a um entendimento ou, o que dá no mesmo, a uma síntese. Nessa menção se percebe o lugar crucial que Blanchot dá a Heráclito na fundação e nos abalos do pensamento no ocidente.

Tentar arranhar a superfície da água pode ser um jogo; A inscrição pessoal é, por sua vez, em tantos casos, rasurada pelo impessoal que a apaga e que pode ser o pessoal de um outro. Maurice Blanchot, falando de literatura, nela procura interferir, e por ela é riscado de volta. Chamar sua obra de autoritária, nesse sentido, é inútil, por dois motivos: a) ele, em geral, evita uma hermenêutica tradicional, explicativa, da obra como um segredo a ser revelado ou uma equação a ser resolvida; b) quanto ao que é descritivo na produção de Blanchot, é preciso lembrar que qualquer descrição tem algo de normativo: descrever já é tentar convencer. Por isso, exercer poder não é apenas inevitável, mas recomendável a qualquer leitor ou ator (social, por exemplo), indivíduo ou grupo. A obra artística, em sua relativa indisponibilidade, aceita e mesmo pede uma investida resoluta do crítico; contemplá-la é tentar interferir nela e pensar esse ato como um fracasso quase certo e necessário. A arte, em seu desacordo de imagem com o que se vê e com o que não se vê, pode ser defrontada com uma outra imagem, que é o próprio discurso crítico ou filosófico, o qual, se não toca a obra, pode afastá-la de lugar: eis a interferência. Arte e filosofia/crítica são interlocutores numa conversa que ainda não acabou e que talvez seja infinita. Nenhum dos dois venceu até agora; a crítica tenta dominar a arte, que arisca, foge, depois de arranhar a outra com suas garras.

Essas observaçóes podem fazer pensar sobre que tipo de exercício de crítica literária seria a obra de Blanchot. Como dito, ela não se presta a ser aplicada como fórmula ou como chave de leitura geral para obras singulares, e não serviria, então, como confirmação ou explicação, como gesto acalentador pelo qual alguém diria: "fiquem tranquilos, há uma realidade segura e infalível para vocês amarem-na ou odiarem-na". Longe disso, a ideia é pensar a filosofia/literatura do autor francês como metodologia da dissonância, da disparidade que se desenvolve como obra frente aos leitores. Ler Blanchot em grupo, por exemplo, é caminho fácil para leituras díspares. Nessa visão, saber como 
uma leitura interfere na obra lida, e como esta interfere naquela, é provavelmente mais relevante que saber quantas pessoas depositariam naquela leitura um ato de fé (por mais científico que este queira ser) pelo qual ela, aquela leitura, seria convencionada como realidade inquestionável. E isso, não em nome de um suposto niilismo ${ }^{30}$, mas da noçáo de que o pensamento está sempre por ser construído e que vive de ameaçar tantas dicotomias tão queridas quanto desgastadas, como bem e mal, concreto e abstrato, forma e conteúdo, etc.

Este discurso aqui, enfim, procura interferir no de Blanchot e é certamente interferido por ele. Meu interlocutor me confirma e me desconfirma. A grande vantagem de haverem diversos e díspares métodos de estudo da literatura é provavelmente a própria disparidade entre eles; a resposta ausente resvala, e, se ela não está aqui, certamente não estará num além qualquer; não será resposta autêntica para quem é vivo, e o morto, afinal, interessa mesmo é como suplemento, contraponto e complicação ao vivo; o inumano interessa como questáo pertinente ao humano. A maneira como este texto interfere no de Blanchot só poderá ser avaliada, pra começo de conversa, com a leitura de L'entretien infini; mas, ao fim destas breves e introdutórias anotaçóes, o que parece realmente importante perguntar é: de que jeito uma obra interfere no que foi dito acima? De que modo o texto de Blanchot interfere nesta fala? A pergunta ecoa silenciosa.
30. "Le Neutre est pour Blanchot réponse inachevée à l'impossible, réponse définitive aux ruses du nihilisme.

Il échappe donc [...] à la philosophie, à la théologie, à la culture et donc au livre. [...] L'absence de livre absente l'autorité unaire du savoir [...]. Si l'absence de livre n'a malgré tout que le livre pour se dire, ou s'entre-dire par la 'pluralité fragmentaire', elle reste toujours-déjà au livre ce que le désœuvrement est à l'œuvre, 'mouvement du détour', ruse active et insensé de l'écriture, effraction du livre, de l'ordre de la phrase et du discours, de l'enrobage par autorité d'une signature, au nom d'une tout autre autorité, au nom de la responsabilité infinie, au nom de l'autre" ["O Neutro é para Blanchot resposta inacabada ao impossível, resposta definitiva às artimanhas do niilismo, ele escapa portanto [...] à filosofia, à teologia, à cultura e portanto ao livro. [...] A ausência de livro ausenta a autoridade unitária do saber $[. .$.$] . Se a ausência$ de livro não tem senão o livro para ser dita, ou ser entredita pela 'pluralidade fragmentária, ela continua sempre-já para o livro o que a inoperância é para a obra, 'movimento de desvio', artimanha ativa e insensata $\mathrm{da}$ escritura, arrombamento do livro, da ordem da frase e do discurso, arrombamento da embalagem pela autoridade de uma assinatura, em nome de uma autoridade inteiramente outra, em nome da responsabilidade infinita, em nome do outro"]. BIDENT, Christophe. Maurice Blanchot: partenaire invisible, 1998, p. 445446. 


\section{Referências}

BIDENT, Christophe. Maurice Blanchot: partenaire invisible. Seyssel: Champ Vallon, 1998.

BLANCHOT, Maurice. "La parole plurielle". In : L'entretien infini. Paris: Gallimard, 1969, p. 1-116.

L'espace littéraire. Paris: Gallimard, 2012 (Folio essais).

BYLAARDT, Cid Ottoni. "Negatividade e morte no pensamento de Maurice Blanchot". Letras de hoje. v. 48, n. 2, p. 182-190, abr. /jun. 2013.

CANDIDO, Antonio. Formação da literatura brasileira: momentos decisivos. Volume único. 9. ed. Belo Horizonte: Itatiaia, 2000.

DERRIDA, Jacques. De la grammatologie. Paris: Les Éditions de Minuit, 2011 (Collection «Critique»). La vérité en peinture. Paris: Flammarion, 1978.

FOUCAULT, Michel. "La pensée du dehors". In :

Dits et écrits I: 1954-1975. Paris: Gallimard, 2001, p. 546-567.

LOPES, Silvina Rodrigues. Literatura, defesa do atrito. Belo Horizonte: Chão da feira, 2012.

MAN, Paul de. "Impersonality in the criticism of Maurice Blanchot". In:__Blindness and insight: essays in the rhetoric of contemporary criticism. Minneapolis: University of Minnesota, 2010, p. 60-78.

PROUST, Marcel. “Le temps retrouvé”. In : À la recherche du temps perdu. Paris: Gallimard, 1999, p. 21292401.

WITTGENSTEIN, Ludwig. Investigaçóes filosóficas. Trad. Marcos G. Montagnoli. 4. ed. Petrópolis: Vozes, 2005. 